\title{
U⿱宀⿻三丨口
}

\section{Promoting Mental Health Awareness in Sport Clubs}

Breslin, G., Haughey, T., Donnelly, P., Kearney, C., \& Prentice, G. (2017). Promoting Mental Health Awareness in Sport Clubs. Journal of Public Mental Health, 16(2), 55-62. https://doi.org/10.1108/JPMH-08-2016-0040

Link to publication record in Ulster University Research Portal

\section{Published in:}

Journal of Public Mental Health

Publication Status:

Published online: 19/06/2017

DOI:

10.1108/JPMH-08-2016-0040

\section{Document Version}

Author Accepted version

\section{General rights}

Copyright for the publications made accessible via Ulster University's Research Portal is retained by the author(s) and / or other copyright owners and it is a condition of accessing these publications that users recognise and abide by the legal requirements associated with these rights.

\section{Take down policy}

The Research Portal is Ulster University's institutional repository that provides access to Ulster's research outputs. Every effort has been made to ensure that content in the Research Portal does not infringe any person's rights, or applicable UK laws. If you discover content in the Research Portal that you believe breaches copyright or violates any law, please contact pure-support@ulster.ac.uk. 


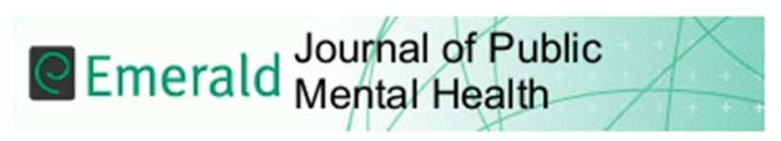

\section{Promoting Mental Health Awareness in Sport Clubs}

\begin{tabular}{|r|l|}
\hline Journal: & Journal of Public Mental Health \\
\hline Manuscript ID & JPMH-08-2016-0040.R1 \\
\hline Manuscript Type: & Original Research Paper \\
\hline Keywords: & resilience, mental toughness, stigma, help seeking \\
\hline \multicolumn{2}{|l}{} \\
\hline
\end{tabular}

SCHOLARONE $^{\text {m }}$

Manuscripts 


\title{
Promoting Mental Health Awareness in Sport Clubs
}

\begin{abstract}
Purpose: The World Health Organization estimate that millions of people across the world experience mental health problems, yet traditionally athletes have been poorly supported to manage their mental health. This study applied the Theory of Planned Behaviour to determine the effect of a mental health awareness programme on sports coaches' knowledge and intentions to offer support to athletes who experience mental health problems. Method: Adult coaches $(n=244)$ were recruited to attend the Mood Matters in Sport Programme (MMSP) mental health awareness intervention or act as a control. A 2 (group) x 2 (time) quasi-experimental design was adopted. All participants completed the Mental Health Knowledge Schedule and Reported and Intended Behaviour Scale at the beginning and end of the programme. Findings: A mixed ANOVA showed a significant interaction effect wherein there were improvements in mental health knowledge and intentions to offer support compared to the control group. Practical implications: Knowledge and intentions to offer support can be enhanced through a short mental health awareness programme. The already established social networks available in sport clubs can provide a natural environment for delivering mental health awareness programmes.
\end{abstract}

Originality: This is the first study to apply the Theory of Planned Behaviour to mental health awareness programmes in a sport setting.

Key words: resilience, mental toughness, mental health, stigma, help seeking. 


\section{Introduction}

Mental health is defined as 'a state of well-being in which every individual realises his or her own potential, can cope with the normal stresses of life, can work productively and fruitfully, and is able to make a contribution to her or his community' (World Health Organization, 2014). The World Health Organization (2011) estimate that millions of people across the world experience mental health problems, with one in four experiencing a mental illness at some point in their lives. Despite the common occurrence, few young people with a diagnosable mental illness receive professional help (World Federation for Mental Health, 2009; Green, McGinnity, Meltzer et al, 2006; Biddle, Donovan, Gunnell, et al. 2006; Burns, Costello, Angold, et al. 1995) with the costs incurred by late detection or untreated mental illnesses being considerable. Health promoters have a pivotal role to play in reducing stigma associated with having a mental health problem. These professionals should encourage those who may be at risk of mental ill health to seek help or assist in making important health-related lifestyle changes. While primary care and schools should be key sites in terms of prevention, recognition, early intervention and referral to services, there is evidence that many young people fail to seek help from these sources (Rothi and Leavey, 2006; Rothi, Leavey, Best, et al. 2005). This may be due to a combination of stigma surrounding mental health, a lack of information about support or the mistrust of health professionals and authority figures (Leavey, Rothi, and Paul, 2011).

Unlike physical health, it is argued that mental health has not been accorded the same importance by the public. Breslin and McCay (2013) showed participants have more perceived control over their physical compared to mental health. Their 
findings, interpreted within the Theory of Planned Behaviour (Azjen, 1985),

illustrated the increased need for health behaviour change to be directed at enhancing perceived control over mental health. Using the Theory of Planned Behaviour to predict intentions to adopt healthy behaviours, lower perceived control by respondents over mental health outcomes may be associated with less participation or adherence to lifestyle choices and behaviours with protective benefits for mental health. Therefore, mental health promotion efforts should focus on; (a) bridging the gap between how stigma influences intentions to seek help, and (b) how a person can make the transition from intention to seek help, to actually seeking help. To this end, there have been creative attempts to promote positive mental health messages to support those with mental health problems. One attempt has been through the delivery of mental health awareness messages in a sport setting or via online programmes (Gulliver et al., 2012; Sebbens, Hassmén Crisp and Wensley, 2016). Within this environment, programmes have been delivered to athletes or coaches. In this domain, athletes were selected to increase their knowledge of mental health literacy while coaches were selected due to their established working relationships and close proximity with athletes (Sebbens et al, 2016).

Sport has been shown to be a useful medium to tackle mental health as it provides a natural environment for an established social community network. This network emanates in a substantial level of trust across players, coaches, parents and the wider community (Breslin, Dennelly, Kearney and Haughey, 2015)providing an opportunity for engagement in mental health awareness (Breslin, Donnelly, Kearney and Haughey, 2015). However, despite the positives, sport environments can present challenges. According to Bauman (2016), athletes traditionally have been poorly 


\section{Mental Health Awareness In Sport Clubs}

supported to manage their mental health and instead, the sporting culture has celebrated mental toughness and disapproval of weakness disclosure. Consequently, with this lack of mental health support, emotional and psychiatric problems can remain hidden (Trojian, 2016), and the development of stigma can prevent athletes from seeking timely and appropriate help (Bauman, 2016). In response to the uncertainties of whether mental health awareness programmes in sport are effective, a recent systematic review concluded that programmes delivered to athletes and coaches have been effective (Breslin, Shannon, Haughey, Donnelly and Leavey, under review). Not included within the Breslin et al review, a recent study by Sebbens et al, (2016) was conducted with coaches and support staff within the elite sport environment. The findings revealed increases in mental health awareness and confidence in providing support to someone with a mental health problem, the effects were maintained at follow-up compared to controls.

In the current study, we tested the effects of providing a mental health awareness intervention, the Mood Matters in Sport Programme (MMSP), to paid and volunteer coaches. The sample consisted of amateur sports with the purpose of increasing their knowledge of mental health and intentions to offer help to those who have a mental health problem. A psychological theory of behaviour change, the Theory of Planned behaviour (Azjen, 1985) was applied. Three directional hypotheses were assessed: i) coaches who received the MMSP will be significantly more knowledgeable of mental health than those in a control group; ii) coaches who receive the intervention will be significantly more likely to offer support to someone with a mental health problem, and; iii) there will be a significant positive correlation 


\section{Mental Health Awareness In Sport Clubs}

between mental health knowledge and intention to offer support to a person with a mental health problem for those coaches in the intervention group.

\section{Method}

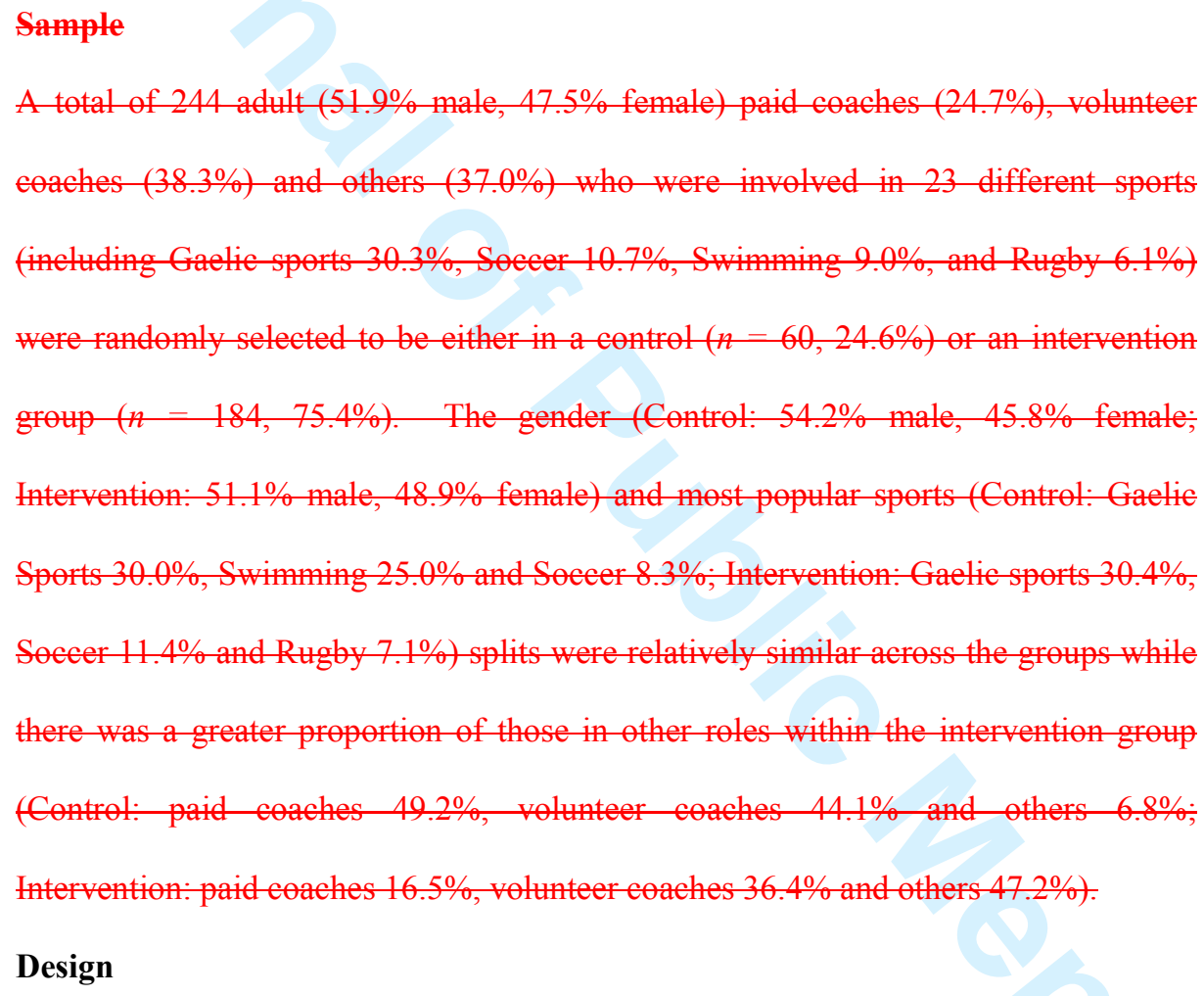

A quasi experimental approach was taken. A randomised control trial was not feasible due to training being delivered at several locations and recruitment of the intervention group taking place first, followed by recruitment of the control participants. The intervention group received the Mood Matters in Sport Mental Health Educational Programme while the control group received a coaching programme without mental health content, to act as comparison and matched for time. Participants were recruited via email and telephone calls to clubs. Questionnaires were completed before and after the intervention. The questionnaires were based on 


\section{Mental Health Awareness In Sport Clubs}

questions previously used by Northern Ireland's Public Health Agency's evaluation of Mental Health First Aid (MHFA, 2006); and a general public mental health literacytraining programme also conducted in Northern Ireland. The variables measured included mental health stigma related behaviour (Reported and Intended Behaviour Scale - RIBS; Evans-Lacko et al, 2011), Mental Health Knowledge (a self-report level of mental health knowledge single 5-point ordinal response question, a mental healthrelated testing knowledge question and the MAKS questionnaire: Evans-Lacko et al, 2010), and confidence in ability to help someone with a mental health problem (a single 5-point ordinal response question).

\section{Measures}

Reported and Intended Behaviour Scale (RIBS: Evans-Lacko et al, 2011)

The RIBS measures mental health stigma related behaviour that can be used on a general public sample. Items 1-4 address the respondents' exposure to individuals with mental health problems through examining whether they live or work with, or have a neighbour, or close friend, with a mental health problem. Items 1-4 response options are yes, no or don't know. As items 1-4 relate to the prevalence of behaviours they are not scored nor summed in any way. Items 5-8 response options follow an ordinal format (1-5), ranging from strongly agree (5) to strongly disagree (1), and relate to intended behaviours in relation to willingness to live, work, live nearby or continue a relationship with someone with a mental health problem. Items 5-8 can be summed, and after a confirmatory factor analysis of baseline data in the current study revealed a good fit one factor model representing these items (Chi-square $=4.32, \mathrm{df}=$ $2, \mathrm{p}=.115)$, a summed variable was created. This summed variable can range between possible scores of 4 to 20 , higher scores indicating greater willingness/ 
intentions to mix with individuals with mental health problems. Previously the RIBS measure has shown good reliability and validity (Evans-Lacko et al, 2011).

\section{Mental Health Knowledge Schedule (MAKS: Evans-Lacko et al, 2010)}

The MAKS focuses on six stigma-related mental health knowledge areas relating to (1) Help-seeking, (2) Recognition, (3) Support, (4) Employment, (5) Treatment and (6) Recovery. It is scored using an ordinal type scale (1-5), ranging from strongly agree (5) to strongly disagree (1). Responses to items 6, 8 and 12 are reversed. Items 7-12 are used to ascertain recognition and familiarity with various mental health conditions. Items 1-6 can be summed, but after a confirmatory factor analysis conducted on baseline data in the current study did not confirm a one-factor structure. While removal of items 1 and 6 did facilitate a good fitting one factor model representing the items $($ Chi-square $=1.97, \mathrm{df}=2, \mathrm{p}=.373)$, only items $2-5$ were summed to create a new variable. This summed variable can range between possible scores of 4 to 20 , higher scores indicating greater mental health knowledge. Previously the MAKS measure has shown good reliability and validity (Evans-Lacko et al, 2010).

\section{Procedure}

Intervention: The Sport Northern Ireland Mood Matters Educational Programme

The MMSP is a modification of Mood Matters, a -specialises in enhancing-mental health awareness programme that is delivered to the-within the general public. Its syllabus covers the definition of mental health awareness, mental health factors, mental health problems and illnesses, signs and symptoms of mental illness, treatments, self-help strategies and sources of aid. The programme was modified to include videos of athletes who have experienced depression telling of their 
Mental Health Awareness In Sport Clubs

experience. Discussions were also facilitated on identifying what social and environmental factors in sport can influence athlete mental health. -The programme lasted for three hours and was provided by facilitators recognised by a Public Health Agency provider. The pre- and post-intervention questionnaires were given out immediately before and after the intervention took place. Aftercare was offered if participants in the programme experienced any negative effects. The study was conducted after ethical approval was gained from the supporting University's Ethics Filter Committee. After agreement with the ethics-related information provided on a consent form, participants were included in the sample for the study. Any participant who did not provide consent were allowed to receive the intervention without the questionnaire element.

\section{Data Analysis}

Baseline exposure to individuals with mental health problems (RIB items 1-4) was illustrated in Table 1 by a bar chart (Figure 1), split according to control and intervention sample groupings. Pre- and post-intervention percentages were included in table 1 and 2 within side by side bar charts (Figures 25 ) for the ordinal style questions self-reported mental health knowledge, a mental health-related testing knowledge question, confidence in ability to help someone with a mental health problem, and MAKS items 7-12, split according to control and intervention sample groupings. Pearson Product Moment Correlation Analyses (r) were calculated to ascertain the relationship between MAKS Mental Health Knowledge and RIBS willingness/ intentions to mix with individuals with mental health problems, at preand post-intervention split according to sample grouping. A two (Time-points: Pre and Post-Intervention) by four (The four variables: Mental health knowledge, 


\section{Mental Health Awareness In Sport Clubs}

Confidence in ability to help, MAKS Mental Health Knowledge, and RIBS willingness/ intentions to mix) Repeated Measures Analysis of Variance (ANOVA) was conducted based on the control and intervention groupings (the between-groups factor). The bottom of The side by side line plots (Figure 6) $\underline{\text { Table } 2}$ illustrates the interaction between time-points, the four variables and the sampling groupings derived from the Repeated Measures ANOVA.

\section{Results}

A total of 244 adult $(51.9 \%$ male, $47.5 \%$ female) paid coaches $(24.7 \%)$, volunteer coaches $(38.3 \%)$ and others $(37.0 \%)$ who were involved in 23 different sports (including Gaelic sports [Irish team sports: football, hurling and camogie] 30.3\%, Soccer $10.7 \%$, Swimming $9.0 \%$, and Rugby $6.1 \%$ ) were selected to be either in a control $(n=60,24.6 \%)$ or an intervention group $(n=184,75.4 \%)$. The gender (Control: $54.2 \%$ male, $45.8 \%$ female; Intervention: $51.1 \%$ male, $48.9 \%$ female) and most popular sports (Control: Gaelic Sports 30.0\%, Swimming 25.0\% and Soccer 8.3\%; Intervention: Gaelic sports $30.4 \%$, Soccer $11.4 \%$ and Rugby $7.1 \%$ ) splits were relatively similar across the groups while there was a greater proportion of those in other roles within the intervention group (Control: paid coaches $49.2 \%$, volunteer coaches $44.1 \%$ and others $6.8 \%$; Intervention: paid coaches $16.5 \%$, volunteer coaches $36.4 \%$ and others $47.2 \%)$.

When responding to the questionnaires, eExposure to individuals with mental health problems in the past was relatively high within both the intervention and control groups, varying from percentage scoress of the mid 40s to 70s (요 See Figure-Table 1). 
Self-reported mental health knowledge did noticeably improve between pre- and postintervention within the intervention group sample, while the levels of knowledge remained relatively stable within the control group (s See Table 1Figure 2). There was a noticeable shift from 'know a little' to 'knowledgeable' within the intervention group while approximately half the control group remained within the 'know a little' level. This improvement in knowledge between pre and post within the intervention group was even more noticeable in regards to correct responses to a question on the proportion of the population with a mental health problem within their lifetime ( $\underline{s} S e e$ Table 1Figure 3). Correct responses increased from less than $20 \%$ to over $60 \%$ within the intervention group compared to minimal change within the control group.

\title{
Insert Figure 3 here
}

Confidence in ability to help someone with a mental health problem also noticeably improved within the intervention group compared to no noticeable change within the control group (see Table 1See Figure 4). More specifically, there was a noticeable shift to 'moderately' or 'quite a bit' confident within the intervention group while the majority of the control group sample remained within 'a little bit' or 'moderately'.

\author{
Insert Figure 5 here
}


In terms of agreement/correct recognition of some constructs of mental health conditions (Depression, Schizophrenia, Bipolar and Drug addiction) and disagreement/correct recognition that some constructs are not mental health conditions (Stress and Grief), there was relative stability between pre and post for the intervention and control groups (see Table 2See Figure 5), with one notable exception. Within the intervention group there was a noticeable improvement in recognition of bipolar as a mental health condition. Across both samples there was also a lack of recognition of/ agreement with, drug addiction as a mental health condition, while most correctly disagreed with stress and grief as mental health conditions.

$$
\mid
$$

Pearson Product Moment Correlation Analyses (r) were calculated to ascertain the relationship between MAKS Mental Health Knowledge and RIBS willingness/intentions to mix with individuals with mental health problems, at preand post-intervention ${ }_{2}$ was split according to sample grouping. A significant positive weak to moderate correlation remained between MAKS Mental Health Knowledge and RIBS willingness/intentions to mix with individuals with mental health problems, at pre- $(\mathrm{r}(137)=.38, \mathrm{p}<.001)$ and post-intervention $(\mathrm{r}(149)=.22, \mathrm{p}=.006)$. Greater levels of mental health knowledge paralleled greater intentions to mix with individuals with mental health problems, within the intervention group. This significant relationship did not occur within the control group, with non-significant correlations resulting at pre- $(\mathrm{r}(49)=.18, \mathrm{p}=.220)$ and post-intervention $(\mathrm{r}(52)=$ $.19, \mathrm{p}=.171)$ 


\section{Mental Health Awareness In Sport Clubs}

Insert Figure 6 here

A mixed design repeated measures ANOVA, using the Greenhouse Geisser correction, showed that there was a significant interaction between time-point, variable and group $(\mathrm{F}(3,364)=13.14, \mathrm{p}<.001)$. In other words, the change between pre- and post-intervention within the variables depended on whether the respondents were in the intervention or control sample grouping (see Table 2See Figure 6). Within the intervention group, there were significant improvements in mental health knowledge estimated marginal means between pre- and post-treatment (2.17 to 2.86 ) while the same variable remained stable in the control group (2.29 to 2.31). In relation to confidence in ability to help someone with a mental health problem, there was also a significant improvement from pre- to post-intervention within the intervention group (2.34 to 3.16 ) while the same variable remained stable within the control group (2.53 to 2.55). Mental health knowledge (MAKS) also significantly improved between pre- and post-intervention (16.10 to 18.41$)$ within the intervention group but remained stable within the control group (16.53 to 16.45$)$. Intentions to mix with individuals with mental health problems also significantly improved within the intervention group (17.82 to 18.78$)$ but remained stable within the control group (17.71 to 17.67$)$.

\section{Discussion}

The aim of the current study was to determine whether providing a mental health awareness intervention to coaches increased their knowledge of mental health and intentions to provide support to others.

Coaches' knowledge of mental health increased as did their intentions to offer support to someone with a mental health problem. Furthermore, correlational analysis 
showed greater levels of mental health knowledge, paralleled greater intentions to mix with individuals with mental health problems within the intervention but not for the control group. A person's willingness to spend time or have a relationship with a person with a mental health problem, as shown by the intervention group, can indicate a reduction in levels of stigma. This finding was not present in the control group.

When interpreted via the Theory of Planned Behaviour (Ajzen, 1985), an increase in knowledge and understanding of mental health predicts an increase in intentions to offer support to others. These findings are in support of Breslin and McCay (2013) on the relationship between perceived control over mental health and help seeking behaviour. The findings also support a recent study conducted in an elite sport performance environment (Sebbens et al., 2016) and extends the use of a psychological theory of behaviour change: the TPB to mental health and awareness programmes in sport.

In terms of correct recognition of mental health conditions, there was relative stability between pre and post time points for the intervention and control groups. The lack of difference between the control and intervention groups maybe due to the public mental health awareness campaigns, Minding Your Head that took place around the time of the intervention (http://www.mindingyourhead.info/). An additional benefit of taking part in the intervention was a noticeable improvement in recognition of bipolar disorder as a mental illness. Across both groups there was a lack of recognition and agreement about drug addiction as a mental health condition, it was not included in the MMSP and could be considered for inclusion given some previous research in sport settings, and the risk of substance misuse (Donohue et al., 2014). 
randomised into groups, therefore a pspotential bias in who was recvuited tyo nthe intervention group could have occurred. A more thorough randomised controlled trial is required to enhance the robustness of the evaluation. Also, and it was not possible to determine whether the training actually led to a coach supporting someone in their club who was experiencing a mental health problem or requiring support. Thisis is an is an_ important point, as according to the TPB, intention predicts behaviour change. Our data does not allow us to infer that even with confidence to provide support the person has actually provided support. Further follow up is required to determine the suitability of the programme for behaviour change (offering mental health support). Future studies should include a longer term follow up, incorporate a qualitative component to gain the individual experiences of the participants and we also recommend that other components of TPB are included that were not included in the current study, such as; an assessment of attitudes to mental health, and a measure of social relatedness (Ajzen, 1985).

In conclusion, a short mental health awareness psycho-education programme can increase knowledge of mental health including knowledge of mental disorders beyond that of a control group. The MMSP can also increase intentions to offer help and support to someone with a mental health problem. Based on our findings it may be worthwhile to continue with dissemination of the workshop in club settings to coaches and perhaps tailoring of the workshop for parents, teenagers, or a specific sport. Within Northern Ireland, where the study was conducted, mental health and wellbeing in sport courses such as MMSP could be considered an integral part in the development of coach education, player welfare and safe guarding players. Based on 


\section{Mental Health Awareness In Sport Clubs}

the findings from the current study and the Breslin et al (under review) systematic review the government organisation for sport in Northern Ireland where the study took place have taken steps to develop a mental health and wellbeing in and through sport strategy to raise mental health issues in sport for athletes, coaches and parents (Sport Northern Ireland, 2016).

\section{References}

Ajzen, I. (1985), "From intentions to actions: A Theory of Planned Behaviour", in Kuhl, J. and Beckman, J. (Ed.) Action Control: From Cognition to Behaviour. Springer, New York, pp. 11-39.

Bauman, N. J. (2016), "The stigma of mental health in athletes: Are mental toughness and mental health seen as contradictory in elite sport?" British Journal of Sports Medicine, Vol.50 No. 3, 135-136. doi:10.1136/bjsports-2015-095570.

Biddle, L. Donovan, J. Gunnell, D. et al. (2006), "Young adults' perceptions of GPs as a help source for mental distress: a qualitative study", British Journal of General Practice, Vol.56 pp. 924-31.

Breslin, G. Donnelly, P. Kearney, C., and Haughey, T. (2015), Mental health and wellbeing in Sport, A pilot educational programme for clubs. Sport Northern Ireland. Accessed August $30^{\text {th }} 2016$ http://www.sportni.net/sportni/wp- 
Mental Health Awareness In Sport Clubs

content/uploads/2015/10/Mental-Health_Wellbeing-inSport-Final-Research-

Breslin, G. \& McCay, N. (2013), "Perceived control over physical and mental wellbeing: the effects of gender, age and social class". Journal of Health Psychology, Vol.18 No.1, pp.38-45. doi: 10.1177/1359105312438600.

Breslin, G. Shannon, S. Haughey, T. J. Donnelly, P. and Leavey, G. (Under Review), "A systematic review of interventions to increase awareness of mental health and wellbeing in athletes and coaches".

Burns, B, J. Costello, E, J. Angold, A. et al. (1995), "Children's mental health service use across service sectors". Health Aff. Vol.14, No 3, pp.147-59.

Evans-Lacko, S. Little, K. Meltzer, H. Rose, D. Rhydderch, D. Henderson, C.

Thornicroft, G. (2010), "Development and Psychometric Properties of the Mental Health Knowledge Schedule (MAKS) ". Canadian Journal of Psychiatry, Vol. 55, pp. $440-448$

Evans-Lacko, S. Rose, D. Little, K. Flach, C. Rhydderch, D, Henderson, C. Thornicroft, G. (2011), "Development and Psychometric Properties of the Reported and Intended Behaviour Scale (RIBS): A Stigma Related Behaviour Measure". Epidemiology and Psychiatric Sciences. Vol. 20, pp. 263-271. 
Gulliver, A. Griffiths, K. M. and Christensen, H. (2012), "Barriers and facilitators to mental health help-seeking for young elite athletes: a qualitative study". $B M C$

Psychiatry, Vol.12, pp.157. doi: 10.1186/1471-244X-12-157.

Leavey, G. Rothi, D. Paul, R. (2011), "Trust, Autonomy and Relationships: The HelpSeeking Preferences of Young People in Secondary Level Schools in London (UK) ". Journal of Adolescence, Vol.34, No.4, pp.685-93.

Mental Health First Aid (2006), An evaluation of mental health first aid trainers in Northern Ireland. Health Promotion Agency for Northern Ireland. Belfast.

Serfaty, M. (2007), "The Stigma Scale: development of a standardised measure of the stigma of mental illness". British Journal of Psychiatry, Vol.19, pp. 248- 254.

Sport Northern Ireland, (2016). "Mental health and wellbeing in and through sport strategy development group". Sport Northern Ireland, Belfast.

Rothi, D. and Leavey, G. (2006), "Mental Health help-seeking and young people: a review". Pastoral Care in Education, Vol.24, No. 3. pp.4-13. 


\section{Mental Health Awareness In Sport Clubs}

Rothi, D. Leavey, G. Best, R. et al (2005). "Identification \& Management of Pupils with Mental Health Difficulties: A Qualitative Study of UK Teachers' Experience and Views". Birmingham: National Association of Schoolmasters Union Women Teachers (NASUWT).

Tracy, S. J. (2010). Qualitative quality: Eight "big-tent” criteria for excellent qualitative research. Qualitative Inquiry, Vol.16, No. 10, pp.837-851.

Trojian, T. (2016), Depression is under-recognised in the sport setting: time for primary care sports medicine to be proactive and screen widely for depression symptoms. British Journal of Sports Medicine. Vol.50, No.3, pp.133-134.

Ortlipp, M. (2008), "Keeping and using reflective journals in the qualitative research process". The Qualitative Report, Vol. 13. No. 4. pp. 695-705.

Sebbens, J. Hassmén, P. Crisp, D. and Wensley, K. (2016), "Mental Health in Sport (MHS): Improving the Early Intervention Knowledge and Confidence of Elite Sport Staff ". Front Psychol. Vol.24, No.7. pp.911. doi: 10.3389/fpsyg.2016.00911.

World Federation for Mental Health (2009). Mental Health in Primary Care:

Enhancing Treatment and Promoting Mental Health. Secondary Mental Health in Primary Care: Enhancing Treatment and Promoting Mental Health. http://www.wfmh.org/00WorldMentalHealthDay.htm. 
World Health Organization. (2011). Mental Health Atlas. Geneva.

World Health Organization. (2014). Mental Health: A State of Well-being, Geneva 
Table 1. Percentages relating to mental health problems, exposure, knowledge and confidence in ability to help.

\begin{tabular}{|c|c|c|c|c|}
\hline \multicolumn{5}{|c|}{ Exposure to individuals with mental health problems } \\
\hline & \multicolumn{2}{|c|}{ Intervention } & \multicolumn{2}{|c|}{ Control } \\
\hline Lived with & \multicolumn{2}{|c|}{$44.8 \%$} & \multicolumn{2}{|c|}{$46.6 \%$} \\
\hline Worked with & \multicolumn{2}{|c|}{$56.9 \%$} & \multicolumn{2}{|c|}{$63.3 \%$} \\
\hline Neighbour & \multicolumn{2}{|c|}{$55.1 \%$} & \multicolumn{2}{|c|}{$61.0 \%$} \\
\hline Close friend & \multicolumn{2}{|c|}{$70.1 \%$} & \multicolumn{2}{|c|}{$63.2 \%$} \\
\hline \multicolumn{5}{|c|}{ Self-reported level of mental health knowledge } \\
\hline & \multicolumn{2}{|c|}{ Intervention } & \multicolumn{2}{|c|}{ Control } \\
\hline & Pre & Post & Pre & Post \\
\hline Know very little & $18.0 \%$ & $2.4 \%$ & $13.3 \%$ & $10.0 \%$ \\
\hline Know a little & $57.4 \%$ & $24.6 \%$ & $50.0 \%$ & $55.0 \%$ \\
\hline Knowledgeable & $23.0 \%$ & $66.6 \%$ & $33.3 \%$ & $31.7 \%$ \\
\hline Very knowledgeable & $1.6 \%$ & $6.6 \%$ & $3.3 \%$ & $3.3 \%$ \\
\hline
\end{tabular}

\begin{tabular}{|c|c|c|c|c|}
\hline The proportic & pulatior & nental $h$ & blems & ir lifeti \\
\hline & & & & \\
\hline & Pre & Post & Pre & Post \\
\hline Correct answer & $18.0 \%$ & $61.8 \%$ & $16.0 \%$ & $14.8 \%$ \\
\hline
\end{tabular}

Confidence in ability to help someone with a mental health problem

Intervention

Control

\begin{tabular}{lcccc} 
& Pre & Post & Pre & Post \\
\hline Not at all & $22.1 \%$ & $3.0 \%$ & $11.9 \%$ & $10.0 \%$ \\
A little bit & $44.2 \%$ & $24.6 \%$ & $37.3 \%$ & $41.7 \%$ \\
Moderately & $23.8 \%$ & $37.7 \%$ & $37.3 \%$ & $35.0 \%$ \\
Quite a bit & $10.0 \%$ & $34.7 \%$ & $13.6 \%$ & $13.3 \%$ \\
\hline
\end{tabular}




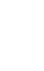


Table 2. Means and Standard Deviations relating to mental health familiarity, knowledge, confidence and intentions to help.

\begin{tabular}{lcccc}
\hline \multirow{4}{*}{ Familiarity with various mental health conditions (MAKS 7-12) } \\
& \multicolumn{2}{c}{ Intervention } & Control & \\
& Pre & Post & Pre & Post \\
\hline Depression & 4.8 & 4.9 & 4.8 & 4.8 \\
Stress & $(0.6)$ & $(0.5)$ & $(0.5)$ & $(0.5)$ \\
Schizophrenia & 2.1 & 2.1 & 2.4 & 2.4 \\
& $(1.3)$ & $(1.5)$ & $(1.3)$ & $(1.2)$ \\
Bipolar & 4.8 & 4.9 & 4.7 & 4.8 \\
& $(0.5)$ & $(0.3)$ & $(0.8)$ & $(0.7)$ \\
Drug addiction & 3.7 & 4.9 & 4.7 & 4.7 \\
& $(0.5)$ & $(0.5)$ & $(0.8)$ & $(0.7)$ \\
Grief & 3.7 & 3.7 & 3.1 & 3.2 \\
& $(1.3)$ & $(1.6)$ & $(1.5)$ & $(1.5)$ \\
& 2.3 & 2.1 & 2.6 & 2.6 \\
& $(1.3)$ & $(1.5)$ & $(1.4)$ & $(1.3)$ \\
\hline \multirow{4}{*}{ Time-point change across variables } & \\
Mental health & Intervention & & Control \\
knowledge & Pre & Post & Pre & Post \\
Confidence & 2.2 & 2.9 & 2.3 & 2.3 \\
& $(0.8)$ & $(0.7)$ & $(0.8)$ & $(0.7)$ \\
Mental health & 2.3 & 3.2 & 2.5 & 2.6 \\
knowledge (MAKS) & $(1.1)$ & $(1.0)$ & $(1.0)$ & $(1.0)$ \\
Intentions to help & 16.1 & 18.4 & 16.5 & 16.5 \\
& $(2.4)$ & $(2.1)$ & $(2.3)$ & $(2.0)$ \\
\hline Note & 17.8 & 18.8 & 17.7 & 17.7 \\
& $(2.7)$ & $(2.4)$ & $(2.6)$ & $(2.3)$ \\
\hline
\end{tabular}

Note: The Standard Deviations are the italic figures in brackets 